\title{
POLÍTICAS EDUCACIONAIS BRASILEIRAS: UMA REFLEXÃO SOBRE O ACESSO À EDUCAÇÃO INCLUSIVA ${ }^{1}$
}

\author{
EDUCATIONAL BRAZILIAN LAWS: \\ A REFLECTION ABOUT THE ACCESS TO AN INCLUSIVE EDUCATION
}

\author{
Renata Quinhones Pereira ${ }^{2}$, Graciela Beck de Bitencourt dos Santos ${ }^{3}$, \\ Clarice Rosa Machado ${ }^{4}$ e Juliane Marschall Morgenstern ${ }^{5}$
}

\section{RESUMO}

Partindo do pressuposto de que a vida social está em constante transformação, compreender o direito à educação a partir de alguns documentos e leis que oferecem representações, normatividades e fomentam ações em prol de sua aplicação, mostrou-se como um fecundo espaço para discussões, permeado por desafios educacionais que se perpetuam na contemporaneidade. O presente artigo revisita documentos legais como a Constituição Federal (1988), a Lei de Diretrizes e Bases da Educação Nacional (9.394/96), o Estatuto da Criança e do Adolescente (8.069/90) e a Política Nacional de Educação Especial na Perspectiva da Educação Inclusiva (2008), objetivando uma reflexão sobre a garantia legal de acesso e permanência do aluno incluído na escola comum a partir das condições para a aprendizagem efetiva. Dessa forma, realizou-se a análise de uma jurisprudência do Tribunal de Justiça do Rio Grande do Sul (TJRS) que versa sobre um estudante com síndrome de Down que requereu, por via judicial, o acompanhamento de monitor educacional especializado. O diálogo construído no estudo, apresenta-se como um fértil horizonte com novas possibilidades de interpretar e reler os mais diversos temas que envolvem a educação e podem ser ajustados, nas suas aplicações, a situações reais no contexto escolar.

Palavras-chave: Constituição Federal, Estatuto da Criança e do Adolescente, Lei de Diretrizes e Bases da Educação Nacional, Educação Especial.

\section{ABSTRACT}

From the assumption that social life is constantly changing, understanding the right to education from some documents and laws that offer representations, normativities and foster actions to its applications, the right to education has been considered as an interesting space for discussions, full of educational challenges that have been perpetuated in the contemporaneity. This article revisits legal documents as the Federal Constitution (1988), the Brazilian National Education Guidelines and Bases Law (9.394/96), the Child and Adolescent Statute (8.069/90) and the National Politics of Special Education in the Inclusive Education Perspective (2008). The main objective of this study is a reflection about the legal guarantee of

\footnotetext{
1 Resultado de trabalho de pesquisa desenvolvido no Grupo de Estudos sobre Políticas Educacionais e Inclusão (GEPEI) Universidade Franciscana (UFN).

2 Mestra em Ensino de Humanidades e Linguagens (UFN). Bacharela em Direito (FAPAS).E-mail: renata_quinhones@, hotmail.com

3 Mestra em Ensino de Humanidades e Linguagens (UFN). Especialista em Leitura, Produção, Análise e Reescritura Textual (URI). Graduada em Letras Português/Inglês e Respectivas Literaturas (URI). Docente do Instituto Federal de Educação, Ciência e Tecnologia Farroupilha - Campus São Vicente do Sul. E-mail: gracielabbitencourt@gmail.com

4 Mestra em Ensino de Humanidades e Linguagens (UFN). Licenciada em Filosofia (UFN). E-mail: clarice.r.machado@, gmail.com

5 Doutora em Educação (UNISINOS). Mestra em Educação (UFSM). Especialista em Gestão Educacional (UFSM). Graduada em Educação Especial e em Pedagogia (UFSM). E-mail: julianemm@ufn.edu.br.
} 
access and permanence of the included student in an ordinary school with effective conditions of learning. This way, it was accomplished an analysis of the Rio Grande do Sul Justice Court jurisprudence (TJRS) that talks about a student with Down's syndrome that required, by the law, the accompany of an specialized educational monitor. The dialogue built in this study showed that it is an area that can be explorated with new possibilities to understand and reread several themes that involve the education and can be adjusted in real situations in the scholar context.

Keywords: Federal Constitution, Child and Adolescent Statute, Brazilian National Education Guidelines and Bases Law, Special Education.

\section{INTRODUÇÃO}

Ao falar em inclusão no presente há de se considerar muitas percepções acerca desse termo. A inclusão pode ser um ideal a ser atingido, uma ideia a ser pensada ou um conceito a ser convertido em ação. Parece que muito já foi dito sobre inclusão e que há pouco a falar sobre a educação inclusiva. Acredita-se que a inclusão tornou -se uma verdade do nosso tempo e que se tem experienciado uma matriz de ação desde a qual vivemos e nos constituímos como sujeitos inclusivos (LOPES e MORGENSTERN, 2014). Nessa direção, não se pode mais, simplesmente, ser contra ou a favor da inclusão, mas pode-se compreendê-la como um conjunto de práticas que modificam a forma de viver com o outro, tanto aquele outro deficiente ou a ser incluído como em relação aquele outro dito normal.

Para refletir sobre os processos inclusivos, cabe atentar para o aumento significativo de alunos incluídos nas escolas brasileiras, onde percebe-se um movimento pela inclusão de todos, com práticas que se deslocaram de um contexto de integração para um contexto de inclusão. A partir da década de 1980, consolidou-se, no país, uma preocupação em torno da necessidade de renovação escolar que colocou a criança como centro das práticas educativas e a necessidade crescente de democratização dos espaços de ações sociais e de participação da população nas decisões políticas do país. Com isso, também se observou o crescimento das políticas de inclusão que passaram a orientar a conduta dos indivíduos e grupos sociais. Assim, a Constituição de 1988 e as discussões realizadas no cenário mundial deram condições para que a inclusão pudesse emergir no Brasil no final da década de 1990. Tatiana Rech (2010), em seu estudo das políticas educacionais brasileiras analisou os discursos de integração e inclusão escolar no Governo de Fernando Henrique Cardoso mostrando que a noção de integração se esmaece na passagem do primeiro mandato (1995-1998) para o segundo mandato (1999-2002) daquele Governo. Embora se deixe de falar em integração para enfatizar os processos de inclusão, é possível verificar que em muitas práticas sociais e escolares, a integração seguiu determinando o que se entendia por inclusão. Em um contexto de redemocratização, a necessidade de que todos se tornassem atuantes e participativos para serem considerados cidadãos, trouxe a urgência de políticas de inclusão social. É nesse sentido que, no final da década de 1980 e início da década de 1990, os discursos e práticas sobre integração e inclusão se alargam, não apenas no âmbito da educação, mas também no cenário mais amplo da sociedade brasileira. 
Enquanto as operações de integração direcionaram-se à escolarização das pessoas que não estavam inseridas em instituições especializadas ou em escolas, assim como aquelas pessoas que apresentavam alguma deficiência, as operações de inclusão passaram a se direcionar a todos os indivíduos, mobilizando-os pela necessidade de convívio com os outros. Fez-se necessário um investimento, cada vez maior, para que todos, mesmo em níveis e condições de participação diferenciadas, se mantivessem ativos e incluídos nas redes sociais e de mercado (MENEZES, 2011).

No âmbito da educação escolar, a inclusão operou uma importante mudança nos espaços e modos de atendimento aos alunos. As escolas e classes especiais, bem como os demais centros de atendimento voltados aos alunos com necessidades especiais foram progressivamente levados a reduzirem suas intervenções. Nesses espaços, almejava-se a reabilitação para a inserção social e seus profissionais precisavam de uma formação bastante especializada para realizar o atendimento. A lógica da inclusão fez com que esse modelo desse lugar a uma perspectiva de atendimento centrada na escola comum. Os profissionais já não precisavam de uma formação tão especializada, pelo contrário, a formação ficou mais generalista convergindo para uma visão mais ampla e ao mesmo tempo menos específica dos processos pedagógicos, ou seja, todo professor passou a ser responsável pela inclusão (de todos) dos alunos em sua sala de aula. As formas de atendimento que eram variadas, pois havia distintas modalidades de atendimento, deram lugar a uma forma de ação que passou a requerer a presença de todos no mesmo espaço físico. A socialização e a presença física tornaram-se o carro-chefe das primeiras formas de educação inclusiva.

Vemos que a educação especializada que poderia substituir o ensino comum, expressa na Lei No 9.394, de 20 de dezembro de 1996, a qual estabelece as Diretrizes e Bases da Educação Nacional (LDB), desde a Política Nacional de Educação Especial na perspectiva da educação inclusiva de 2008, perde esse caráter substitutivo para assumir funções de complementação ou suplementação do ensino comum. Nesse cenário, os gestores docentes se veem diante de um grande desafio, pois precisam fazer a inclusão acontecer promovendo atividades para todos os alunos que estão em sala, sem distinções e também trabalhando de forma conjunta com os profissionais da educação especial cujo atendimento individualizado acontece na sala de recursos.

Corrobora-se com a ideia de que os alunos precisam ser integrados na vida da escola, no entanto, compreende-se que, em muitos casos é necessário que os professores contem com auxiliares de sala para um auxílio adicional. Além desse apoio que requer uma avaliação e orientação a partir do conhecimento de cada caso, o atendimento regular por diversos profissionais também é importante. Ainda, cabe lembrar que a inclusão deve respeitar cada pessoa em sua singularidade, levando em conta que sua deficiência não deve criar barreiras para seu convívio, nem deve impedir a sua participação, aprendizagem e socialização em diferentes espaços. Nesse sentido, é importante vencer resistências e preconceitos construindo uma rede de estudos e de apoio para o trabalho conjunto nas escolas. 
Adaptar as escolas para a inclusão requer deixá-las acessíveis, reorganizar o seu espaço físico, tais como construir rampas de acesso, preparar espaços de uso coletivo (como salas de aula, laboratórios, quadras, informática) e de uso privativo (como os banheiros), instalar em alguns casos até mesmo elevadores, oferecer materiais didáticos apropriados (como livros em Braille), ter equipamentos dotados de recursos para as deficiências (computadores com elementos de adaptação para cegos ou pessoas com alto grau de deficiência visual, por exemplo), entre outras demandas. Também é preciso melhorar as vias públicas e o acesso às escolas. Entretanto, para que a inclusão aconteça com qualidade são necessários investimentos no âmbito da formação e qualificação de recursos humanos, não é possível adaptar relações e formas de convívio, é preciso transformar o modo de pensar e agir em relação aos alunos com necessidades especiais para que o trabalho pedagógico e multiprofissional aconteça com qualidade, além de ter garantido o apoio de monitores e profissionais capacitados para realizar o acompanhamento dos alunos incluídos no espaço da escola comum.

Ao observar os dados do Censo Escolar no Brasil, é possível verificar um crescimento expressivo das matrículas de alunos em situação de inclusão na educação básica do país. Percebe-se que de 200 mil pessoas matriculadas na educação básica, sendo $13 \%$ das matrículas em classes comuns no final dos anos de 1990, passamos a quase 900 mil matrículas, das quais 79\% em classes comuns, no ano de 2014 .

Os dados do IBGE, por sua vez, em levantamentos feitos na Pesquisa Nacional por Amostra de Domicílios (PNAD), realizada em 2009, apontam aproximadamente 2 milhões e 500 mil pessoas entre os brasileiros na faixa etária entre 4 e 17 anos que apresentam algum tipo de deficiência, ou seja, crianças e jovens em idade escolar. Trata-se de um dado preocupante ao ser observado que, entre os brasileiros deficientes apurados pelo IBGE e aqueles que efetivamente estão matriculados nas escolas brasileiras, de acordo com dados do Censo Escolar 2010, há mais de um milhão e meio de pessoas que não têm acesso à escola. O INEP contabilizou 928 mil alunos com deficiência ou transtorno global do desenvolvimento matriculados e frequentando salas de aula regulares, evidenciando haver mais alunos com deficiência fora do que dentro da escola comum. Tal situação demonstra que a cada 10 crianças ou adolescentes em idade escolar, apenas 4 delas têm a educação que lhes é prevista nas leis nacionais.

Ainda, cabe considerar que, das 197 mil escolas existentes no país, cerca de 85 mil atendem alunos com deficiência, ou seja, menos da metade. Ampliar este número e criar mais vagas ainda é uma necessidade, mas, sabe-se que também há a necessidade de garantir o suporte humano de acompanhamento dos alunos incluídos para que eles tenham condições de permanecer, com qualidade, na escola comum.

Os dados mencionados elucidam o desafio de uma educação inclusiva e, principalmente, da garantia de recursos humanos para o acompanhamento e atendimento dos alunos em situação de inclusão, bem como requer uma rede multiprofissional para uma educação que contemple as necessidades específicas dos alunos incluídos. Na mesma direção, também pode-se refletir sobre as possibilidades legais que viabilizam o acesso e a permanência de crianças e jovens com deficiência, transtornos globais do desenvolvimento e altas habilidades/superdotação nas escolas comuns. Nesse 
sentido, justifica-se o interesse em observar as normativas legais voltadas à inclusão escolar no que tange ao acompanhamento realizado por monitores nos espaços escolares a partir da busca de casos jurídicos sobre o tema.

Assim, o acesso à educação, garantido no Art. 205 da Constituição Federal de 1988 prevê a educação como um direito de todos os cidadãos e que precisa ser promovida via regime de colaboração entre família, Estado e sociedade. Considerando as leis que visam assegurar o direito de todos à educação, realizou-se uma busca de casos e a percepção de recorrência destes sobre o tema abordado, por meio da análise de um Acórdão do Tribunal de Justiça do Estado do Rio Grande do Sul (TJRS) cuja temática diz respeito à judicialização do acesso à educação, mais especificamente a situação onde um infante com necessidades especiais requer a disponibilização de monitor qualificado para prestar auxílio especializado na instituição de ensino em que o estudante está matriculado.

Neste ponto, cabe referir que muito embora essa busca apresente um estudo de caso, não se desconhece a existência de muitas outras demandas relacionadas ao direito à educação no judiciário brasileiro. Assim, faz-se necessário sinalizar que além de levantar questões acerca da judicialização da educação e sua perspectiva de efetividade, o objetivo do artigo é promover uma discussão pontual sobre como tem se dado a prática de acompanhamento especializado para alunos em situação de inclusão no ensino regular.

Sabe-se que o cotidiano escolar é constituído por vários atores e nesse contexto torna-se necessário o conhecimento acerca dos aspectos jurídicos e políticos que tornam a escola um ambiente que propicie a formação cidadã, ou seja, sujeitos conscientes de seus direitos e deveres para integrar a vida em sociedade.

Dessa forma a referida apresentação e análise do caso concreto leva em conta a convicção acerca da importância de descomplexificar os atos normativos que estabelecem e regulamentam a educação, em especial, a lei maior do nosso país, a Constituição Federal (1988), bem como leis infraconstitucionais como é o caso do Estatuto da Criança e do Adolescente (ECA) Lei No 8.069, de 13 de julho de 1990 e a Lei de Diretrizes e Bases da Educação Nacional (LDB) № 9.394 de 20 de dezembro de 1996.

\section{PONDERAÇÕES ACERCA DO DIREITO À EDUCAÇÃO}

O direito à educação perpassa as dimensões estruturais que se apresentam vivas, na própria consistência do ser humano, o acesso a essa possibilita a admissão do entendimento, "todo o conhecimento constitui, ao mesmo tempo, uma tradução e uma reconstrução" (MORIN, 2017, p. 24).

Em uma oportunidade histórica, por meio da redemocratização do país, o cidadão pode tornar-se ator e, em alguns momentos, autor do processo singular da elaboração da Constituição Federal Brasileira, promulgada em 1988, que, em sua Seção I “Da Educação”, prevê em seu Art. 208: 
O dever do Estado com a educação será efetivado mediante a garantia de:

I - ensino fundamental, obrigatório e gratuito, inclusive para os que a ele não tiverem acesso na idade própria;

II - progressiva extensão da obrigatoriedade e gratuidade ao ensino médio;

III - atendimento educacional especializado aos portadores de deficiência, preferencialmente na rede regular de ensino;

IV - atendimento em creche e pré-escola às crianças de zero a seis anos de idade;

$\mathrm{V}$ - acesso aos níveis mais elevados do ensino, da pesquisa e da criação artística, segundo a capacidade de cada um;

VI - oferta de ensino noturno regular, adequado às condições do educando;

VII - atendimento ao educando, no ensino fundamental, através de programas suplementares de material didático-escolar, transporte, alimentação e assistência à saúde.

$\S 1^{\circ} \mathrm{O}$ acesso ao ensino obrigatório e gratuito é direito público subjetivo.

$\S 2^{\circ} \mathrm{O}$ não-oferecimento do ensino obrigatório pelo poder público, ou sua oferta irregular, importa responsabilidade da autoridade competente.

$\S 3^{\circ}$ Compete ao poder público recensear os educandos no ensino fundamental, fazer-lhes a chamada e zelar, junto aos pais ou responsáveis, pela freqüência à escola (BRASIL, 1988).

Acerca do mesmo tema, a Lei $n^{\circ}$ 9.394/96 (LDB) define e regulariza a organização da educação brasileira com base nos princípios presentes na Carta Maior. Sendo a educação um direito reconhecido, o contorno legal que indica os direitos e deveres está inscrito em leis de caráter nacional, que amplamente buscam assegurar a educação, não somente como uma mera transmissão do saber, mas como um caminho a ser trilhado em prol da formação cidadã.

Enquanto instituição, a educação é responsável pela instrução formal dos sujeitos em uma sociedade através de práticas de socialização e de formação cultural necessárias para a inserção desses sujeitos em determinada sociedade. O que garante "a participação numa forma particular de vida e, ao mesmo tempo, assegura a continuidade cultural e social" (BIESTA, 2017, p. 16). Dessa maneira, "quando se busca refletir sobre a educação é preciso considerar todos esses fatores históricos, sociais, culturais e políticos que influenciam a forma como se constitui a educação" (MACHADO; COLPO; SANTOS, 2020, p. 64).

Do ponto de vista antropológico, a educação constitui um dos recursos mais eficazes para transmitir e aprender os elementos culturais pelos quais o povo ou comunidade em coletividade perpetuam e desenvolvem seu saber-fazer em relação ao mundo, à vida, à sociedade e ao outro (GEERTZ, 1989; BIESTA, 2017).

Ao refletir sobre o texto citado, é possível perceber a preocupação com uma relação entre a prática escolar e as vivências dos estudantes, por essa razão, foi selecionado um caso prático de análise de uma jurisprudência que versa sobre a garantia de acompanhamento, a um infante com necessidades especiais, de um monitor educacional especializado, fato este que representa um dos entraves para os sistemas de ensino.

A situação supracitada, em algumas instâncias, pode ser considerada como um desafio, sendo nesse momento, necessário o embasamento legal para a efetivação de tal direito, assegurado constitucionalmente. 
Nesse sentido, a proposta pedagógica e o regimento escolar precisam basear-se na Carta Maior, em grande medida, porque a norma legal que não estiver em consonância, padece de inconstitucionalidade. Por estar assim assegurado, o respeito à dignidade deve ser o corolário das relações sociais estabelecidas entre os diversos atores da cena escolar, visto a dignidade da pessoa humana constituir-se em fundamento do Estado brasileiro.

Conforme o Art. $6^{\circ}$ da Constituição Federal de 1988, são direitos sociais a educação, a saúde, a alimentação, o trabalho, a moradia, o transporte, o lazer, a segurança, a previdência social, a proteção à maternidade e à infância, a assistência aos desamparados, na forma desta Constituição.

Apesar do ordenamento jurídico pátrio contar com todas legislações e documentos, já mencionados até o momento no estudo, é comum os cidadãos valerem-se do judiciário para terem acesso aos direitos fundamentais que lhes assegura a Constituição Federal de 1988.

Fazendo um recorte para o estado do Rio Grande do Sul, foi selecionada uma demanda julgada recentemente, pelo Tribunal de Justiça Gaúcho, em que o pleito referente ao acesso à educação foi suscitado pelas partes envolvidas. Trata-se do Recurso de Apelação Cível N ${ }^{0} 70084842087^{6}$, interposto por um município do estado do Rio Grande do Sul que foi condenado ${ }^{7}$ a disponibilizar auxílio de monitor educacional a um infante com necessidades especiais, o qual nasceu com Síndrome de Down.

Em sede de recurso, o ente público alegou que o infante já recebia acompanhamento da professora titular e do estagiário. Os Desembargadores integrantes da Câmara Cível do Tribunal de Justiça em comento acordaram, à unanimidade, em negar provimento ao recurso de apelação interposto, mantendo a decisão recorrida.

6 APELAÇÃO CÍVEL. ECA. DIREITO À EDUCAÇÃO. INFANTE QUE APRESENTA NECESSIDADES ESPECIAIS. SÍNDROME DE DOWN. ACOMPANHAMENTO POR MONITOR EDUCACIONAL. CABIMENTO. Da preliminar carência de ação por ausência de interesse processual - $\mathrm{O}$ documento de fl. 26 atesta que há acompanhamento individualizado do menor por parte de estagiário. Ressalto que, embora não haja óbice à atuação de estagiário, não há prova de que o mesmo esteja sendo orientado por professor especializado. Por conseguinte, não há o que se falar em carência de ação na espécie, eis que o atendimento direto por estagiário não atende às diretrizes do Estatuto da Criança e do Adolescente e da Lei de Diretrizes e Bases da Educação. Direito à Educação Inclusiva - O direito à educação, especialmente àquelas crianças e adolescentes que possuam necessidades especiais, constitui direito fundamental social, a ser assegurado com absoluta prioridade, consoante preconiza o artigo 54, incisos III e VII do Estatuto da Criança e do Adolescente, bem como o artigo 208, incisos III e VII, da Constituição Federal. A Lei de Diretrizes e Bases da Educação - Lei no 9.394/96 - em seu artigo $4^{\circ}$, incisos III e VIII e artigo 12, inciso V, igualmente prevê o direito à educação especializada gratuita aos educandos com deficiência e transtornos globais do desenvolvimento. A Lei n ${ }^{\circ}$ 7.853/89 (Lei de Apoio às Pessoas Portadoras de Deficiência), por sua vez, assegura o pleno exercício dos direitos individuais e sociais das pessoas portadoras de deficiências e sua efetiva integração social. Necessidade de Acompanhamento por Monitor Educacional - A necessidade de auxílio do infante por monitor educacional durante as aulas restou, incontestavelmente, estampada pela documentação encartada aos autos. Impõe-se ao ente público efetivar o direito à educação inclusiva, no caso concreto, mediante a contratação de monitor, uma vez que imprescindível ao atendimento educacional e individualizado do aluno. O não fornecimento pode comprometer-lhe o desenvolvimento, a inserção social e a futura qualificação para o trabalho. NEGARAM PROVIMENTO AO RECURSO DE APELAÇÃO. UNÂNIME.(Apelação Cível, No 70084842087, Vigésima Quinta Câmara Cível, Tribunal de Justiça do RS, Relator: Helena Marta Suarez Maciel, Julgado em: 23-02-2021).

7 A sentença foi proferida pelo juízo a quo nos autos de Ação Civil Pública intentada pelo Ministério Público. 
Justificaram que o direito à educação é um direito social garantido constitucionalmente a todos, consoante previsto no Art. $205^{8}$ da Constituição Federal de 1988. Do mesmo modo, a mudança no paradigma jurídico com o advento da Doutrina da Proteção Integral, sustentada no Art. 227, caput, da Constituição Federal declarou ser dever da família, da sociedade e do Estado assegurar, à criança e ao adolescente, com absoluta prioridade, o direito à educação.

Dentre os artigos que embasam o direito à educação na fundamentação teórica da decisão, ressalta-se ainda, em razão da peculiaridade do caso em análise, o Art. 208, incisos III e VII da Constituição Federal de 1988, por tratar do dever do Estado em efetivar a educação mediante, respectivamente: atendimento educacional especializado aos portadores de deficiência, preferencialmente na rede regular de ensino; e atendimento ao educando, em todas as etapas da educação básica, por meio de programas suplementares de material didático escolar, transporte, alimentação e assistência à saúde.

Além da grandeza do direito ora discutido, bem como o reconhecimento da condição de vulnerabilidade por se tratar de criança, a questão analisada ainda abordou o atendimento educacional especializado, o qual também se repete no Art. 54, incisos III e VII do Estatuto da Criança e do Adolescente (ECA).

Já a Lei No 9.394/96 (LDB), a qual estabelece as diretrizes e bases da educação nacional, complementa, trazendo algumas previsões sobre o Atendimento Educacional Especializado (AEE) como forma de tornar acessível ou complementar à escolarização dos estudantes que possuem alguma necessidade especial. A este respeito a lei preleciona:

Art. $4^{\circ} \mathrm{O}$ dever do Estado com educação escolar pública será efetivado mediante a garantia de: $[\ldots]$

III - atendimento educacional especializado gratuito aos educandos com deficiência, transtornos globais do desenvolvimento e altas habilidades ou superdotação, transversal a todos os níveis, etapas e modalidades, preferencialmente na rede regular de ensino;

$[\ldots]$

VIII - atendimento ao educando, em todas as etapas da educação básica, por meio de programas suplementares de material didático-escolar, transporte, alimentação e assistência à saúde; [...] (BRASIL, 1996).

Durante muito tempo a Educação Especial atuou como um sistema paralelo de ensino, sendo os portadores de Deficiência Intelectual atendidos, na maioria das vezes, em espaços como classes, escolas e instituições especiais. A integração ou inclusão de alunos com necessidades especiais no sistema regular de ensino emerge, em nosso país na década de 80 e, desde então, vem sendo amplamente discutida.

As políticas públicas brasileiras têm organizado a modalidade de ensino da Educação Especial a partir da perspectiva da Educação Inclusiva, sempre baseada no princípio de igualdade de oportunidades nos sistemas sociais.

8 Art. 205. A educação, direito de todos e dever do Estado e da família, será promovida e incentivada com a colaboração da sociedade, visando ao pleno desenvolvimento da pessoa, seu preparo para o exercício da cidadania e sua qualificação para o trabalho. 
A Política Nacional de Educação Especial na perspectiva inclusiva busca reafirmar o direito de todos os cidadãos de acessar o ensino regular, desde a Educação Infantil até o Ensino Superior, instituindo a Educação Especial como uma modalidade de ensino e buscando combater o paralelismo da Educação Especial ao ensino comum (TURCHIELLO et al. 2014, p. 38)

À vista disso, o Art. 58 da LDB (Lei No 9.394/96) classifica a educação especial como uma modalidade de educação escolar oferecida preferencialmente na rede regular de ensino, para os educandos com necessidades especiais, dispondo em seus parágrafos sobre a mobilização de recursos especializados para a realização do atendimento:

$\S 1^{\circ}$ Haverá, quando necessário, serviços de apoio especializado, na escola regular, para atender às peculiaridades da clientela de educação especial.

$\S 2^{\circ} \mathrm{O}$ atendimento educacional será feito em classes, escolas ou serviços especializados, sempre que, em função das condições específicas dos alunos, não for possível a sua integração nas classes comuns de ensino regular.

$\S 3^{\circ}$ A oferta de educação especial, nos termos do caput deste artigo, tem início na educação infantil e estende-se ao longo da vida, observados o inciso III do Art. $4^{\circ}$ e o parágrafo único do Art. 60 desta Lei (BRASIL, 1996).

No que tange às instituições de ensino, o Art. 12 da LDB infere que estas terão a incumbência de prover as condições necessárias para a recuperação dos alunos com menor rendimento, assegurando a execução da proposta pedagógica da escola. Ainda sobre o tema, o Art. 59 da mesma lei aduz que os sistemas de ensino deverão assegurar estudantes com deficiência, transtornos globais do desenvolvimento e altas habilidades ou superdotação:

I - currículos, métodos, técnicas, recursos educativos e organização específicos, para atender às suas necessidades;

II - terminalidade específica para aqueles que não puderem atingir o nível exigido para a conclusão do ensino fundamental, em virtude de suas deficiências, e aceleração para concluir em menor tempo o programa escolar para os superdotados;

III - professores com especialização adequada em nível médio ou superior, para atendimento especializado, bem como professores do ensino regular capacitados para a integração desses educandos nas classes comuns;

IV - educação especial para o trabalho, visando a sua efetiva integração na vida em sociedade, inclusive condições adequadas para os que não revelarem capacidade de inserção no trabalho competitivo, mediante articulação com os órgãos oficiais afins, bem como para aqueles que apresentam uma habilidade superior nas áreas artística, intelectual ou psicomotora; V - acesso igualitário aos benefícios dos programas sociais suplementares disponíveis para o respectivo nível do ensino regular (BRASIL, 1996).

Por sua vez, a Lei N 7.853 , de 24 de outubro de 1989, popularmente conhecida como Lei de Apoio às Pessoas Portadoras de Deficiência, assegura o pleno exercício dos direitos deste público e sua efetiva integração social. Assim, ainda que o beneficiário do direito seja o indivíduo como no caso em análise, a lei, dentre outras providências, disciplina a atuação do Ministério Público para a proteção de interesses coletivos, difusos e individuais da pessoa com deficiência, dispondo: 
Art. $2^{\circ}$ Ao Poder Público e seus órgãos cabe assegurar às pessoas portadoras de deficiência o pleno exercício de seus direitos básicos, inclusive dos direitos à educação, à saúde, ao trabalho, ao lazer, à previdência social, ao amparo à infância e à maternidade, e de outros que, decorrentes da Constituição e das leis, propiciem seu bem-estar pessoal, social e econômico. Parágrafo único. Para o fim estabelecido no caput deste artigo, os órgãos e entidades da administração direta e indireta devem dispensar, no âmbito de sua competência e finalidade, aos assuntos objetos esta Lei, tratamento prioritário e adequado, tendente a viabilizar, sem prejuízo de outras, as seguintes medidas:

I - na área da educação:

a) a inclusão, no sistema educacional, da Educação Especial como modalidade educativa que abranja a educação precoce, a pré-escolar, as de $1^{\circ}$ e $2^{\circ}$ graus, a supletiva, a habilitação e reabilitação profissionais, com currículos, etapas e exigências de diplomação próprios;

b) a inserção, no referido sistema educacional, das escolas especiais, privadas e públicas;

c) a oferta, obrigatória e gratuita, da Educação Especial em estabelecimento público de ensino;

d) o oferecimento obrigatório de programas de Educação Especial a nível pré-escolar, em unidades hospitalares e congêneres nas quais estejam internados, por prazo igual ou superior a 1 (um) ano, educandos portadores de deficiência;

e) o acesso de alunos portadores de deficiência aos benefícios conferidos aos demais educandos, inclusive material escolar, merenda escolar e bolsas de estudo;

f) a matrícula compulsória em cursos regulares de estabelecimentos públicos e particulares de pessoas portadoras de deficiência capazes de se integrarem no sistema regular de ensino; [...] (BRASIL, 1989).

No caso em apreço, segundo os Desembargadores do Tribunal de Justiça do Rio Grande do Sul, as provas apresentadas nos autos do processo de origem demonstraram a necessidade de acompanhamento por monitor educacional durante as aulas, aduzindo que o não fornecimento deste pode comprometer o desenvolvimento do educando, bem como sua inserção na sociedade e qualificação profissional futura. Dessa forma, em atenção ao direito do infante à educação inclusiva, deve ao ente público efetivar o fornecimento do profissional pleiteado. Nota-se que mesmo havendo regramento constitucional e infraconstitucional acerca do direito social à educação, o infante necessitou judicializar sua demanda em vista da proteção desse direito.

Dessa forma, verifica-se que embora a gestão educacional aconteça, por meio de aspectos jurídicos e políticos muito bem definidos, nem sempre os profissionais que atuam na área possuem conhecimento acerca da sua responsabilidade legal no exercício da sua função, o que também tem levado à judicialização das relações escolares. Da mesma forma, algumas pistas apontam para o descumprimento da lei pelo próprio Estado, haja vista que constantemente o Poder Judiciário é provocado a fim de mitigar os problemas inerentes ao direito social de acesso à educação.

\section{CONSIDERAÇÕES FINAIS}

O diálogo entre a Educação e a Política Educacional Brasileira possibilita novos questionamentos e alternativas sobre as esferas da vida social, inclusive jurídicas e educacionais que incluem realidades suprimidas, marginalizadas e emergentes na contemporaneidade. Torna-se necessário 
aprender, e no caso, ensinar a conviver em um mundo de pluralidade e diferença que nos auxilie nas tentativas de responder e solucionar os problemas que enfrentamos na atualidade.

Considerando os dispositivos legais que definem a obrigatoriedade de acesso do cidadão à educação, algumas peculiaridades relacionadas com o processo de Inclusão Escolar, que visam incorporar questões da diversidade ao processo educativo, mostram-se, ainda hoje, como atos de esforço sistemático pela busca de igualdade. A proposta de uma educação inclusiva com vistas à proteção e promoção dos direitos humanos visa propiciar processos educativos capazes de formar cidadãos livres e aptos a interpretar os fenômenos sociais que o mundo moderno nos impõe.

Os princípios que regem a educação nacional, enunciados no texto constitucional devem ser ajustados, na sua aplicação, a situações reais no contexto escolar, tais como: o funcionamento dos sistemas escolares, a formação de especialistas e docentes, recursos materiais e imateriais e a participação do poder público.

Mesmo com várias leis, no cenário brasileiro, que versam sobre o contexto educacional, o conjunto das normas jurídico-constitucionais ainda se apresenta como um vasto campo passível de pesquisas sistemáticas na área da educação, principalmente na sua estreita relação com a sociedade e o Estado.

Quando se aborda as políticas educacionais, imediatamente emergem as questões relativas à Lei de Diretrizes e Bases da Educação Nacional ou ao Plano Nacional de Educação. Intuitivamente, professoras e professores compreendem a interface entre direito e educação a partir das normas que o legislador produziu precipuamente para as escolas. Esta intuição não está equivocada, contudo, não podemos deixar de lado o fundamento maior do ordenamento jurídico brasileiro: a Constituição Federal.

\section{REFERÊNCIAS}

BRASIL. Constituição Federal Brasileira. Presidência da República. Brasília, 1988.

BRASIL. Lei de Diretrizes e Bases da Educação Nacional. Presidência da República. Brasília, 1996.

BRASIL. Lei $\mathbf{n}^{\mathbf{0}} \mathbf{7 . 8 5 3}$, de 24 de outubro de 1989. Dispõe sobre o apoio às pessoas portadoras de deficiência, sua integração social, sobre a Coordenadoria Nacional para Integração da Pessoa Portadora de Deficiência - Corde - institui a tutela jurisdicional de interesses coletivos ou difusos dessas pessoas, disciplina a atuação do Ministério Público, define crimes e dá outras providências. Brasília, DF: Diário Oficial da União, 1989.

BRASIL. Lei nº 8.069, de 13 de julho de 1990. Estatuto da Criança e do Adolescente. Brasília, DF: Diário Oficial da União, 1990. 
BRASIL. Ministério da Educação e Cultura. Secretaria de Educação Básica. Diretoria de Educação, de Currículo e Educação Integral. A Política Curricular da Educação Básica: Novas diretrizes curriculares e os direitos à aprendizagem e desenvolvimento. Brasília, 2012.

BRASIL. Ministério da Educação. Secretaria de Educação Especial. Política Nacional de Educação Especial na perspectiva da Educação Inclusiva. Brasília: MEC/SEESP, 2008.

BIESTA, G. Para além da aprendizagem: educação democrática para um futuro humano. Belo Horizonte: Autêntica Editora, 2017.

GEERTZ, C. A interpretação das culturas. Rio de Janeiro: LTC, 1989.

IBGE. Instituto Brasileiro De Geografia E Estatística. Censo Brasileiro de 2010. Rio de Janeiro: IBGE, 2010. Disponível em: https://bit.ly/3jw1jp2. Acesso em: 26 mar. 2021.

INEP. Instituto Nacional de Estudos e Pesquisas Educacionais Anísio Teixeira. Disponível em: http://portal.inep.gov.br/web/guest/inicio. Acesso em: 26 mar. 2021.

LOPES, M. C.; MORGENSTERN, J. M. Inclusão como matriz de experiência. Pro-posições, Dossiê O efeito Foucault na educação, v. 25, n. 2 (74), p. 177-193, mai./ago. 2014.

MACHADO, C. R.; COLPO, C. M.; SANTOS, E. A. G. Os desafios da docência orientada em tempos de pandemia. Disciplinarum Scientia. Série: Ciências Humanas, Santa Maria, v. 21, n. 2, p. 63-80, 2020.

MENEZES, E. C. P. A maquinaria escolar na produção de subjetividades para uma sociedade inclusiva. 2011. 189f. Tese (Doutorado em Educação) - Programa de Pós-Graduação em Educação, Universidade do Vale do Rio dos Sinos, São Leopoldo, 2011.

MORIN, E. A cabeça bem feita. Rio de Janeiro: Bertrand Brasil, 2017.

RECH, T. L. A emergência da inclusão escolar no governo FHC: movimentos que a tornaram uma verdade que permanece. 2010. Dissertação (Mestrado em Educação) - Programa de Pós-Graduação em Educação, Universidade do Vale do Rio dos Sinos - UNISINOS, São Leopoldo, 2010. 
RIO GRANDE DO SUL. Tribunal de Justiça do Estado. Apelação Cível no 70084842087. Eca.

Direito à educação. Infante que apresenta necessidades especiais. Síndrome de down. Acompanhamento por monitor educacional. Cabimento. Negaram provimento ao recurso de apelação. Unânime. Relator: Helena Marta Suarez Maciel, 23 de fevereiro de 2021.

TURCHIELLO, P. et al. Atendimento Educacional Especializado. SILUK, A. C. P.; Atendimento Educacional Especializado: Contribuições para a Prática Pedagógica. Santa Maria: UFSM, CE, Laboratório de Pesquisa e Documentação, 2014. 